\title{
Recent advance in very early-onset inflammatory bowel disease
}

\author{
Jung Ok Shim \\ Department of Pediatrics, Korea University Guro Hospital, Korea University College of Medicine, Seoul, Korea
}

Recent studies on pediatric inflammatory bowel disease (IBD) have revealed that early-onset IBD has distinct phenotypic differences compared with adult-onset IBD. In particular, very early-onset IBD (VEO-IBD) differs in many aspects, including the disease type, location of the lesions, disease behavior, and genetically attributable risks. Neonatal or infantile-onset IBD develops in less than $1 \%$ of pediatric patients. Children with infantile-onset IBD have high rates of affected first-degree relatives and severe disease course. The suspicion of a monogenic cause of VEO-IBD was first confirmed by the discovery of mutations in the genes encoding the interleukin 10 (IL-10) receptors that cause impaired IL-10 signaling. Patients with such mutations typically presented with perianal fistulae, shows a poor response to medical management, and require early surgical interventions in the first year of life. To date, 60 monogenic defects have been identified in children with IBD-like phenotypes. The majority of monogenic defects presents before 6 years of age, and many present before 1 year of age. Next generation sequencing could become an important diagnostic tool in children with suspected genetic defects especially in children with VEO-IBD with severe disease phenotypes. VEO-IBD is a phenotypically and genetically distinct disease entity from adult-onset or older pediatric IBD. (Intest Res 2019;17:9-16)

Key Words: Very early-onset inflammatory bowel disease; Child; Infant; Mutation

\section{INTRODUCTION}

Inflammatory bowel disease (IBD) encompasses a diverse group of complex disorders. There is an increasing amount of evidence that IBD develops in genetically susceptible individuals. Children with IBD not only suffer from the common symptoms of adult-onset IBD, but also exhibit growth failure. ${ }^{1,2}$ Studies on pediatric IBD have revealed that early-onset IBD has distinct phenotypic differences compared to adult-onset

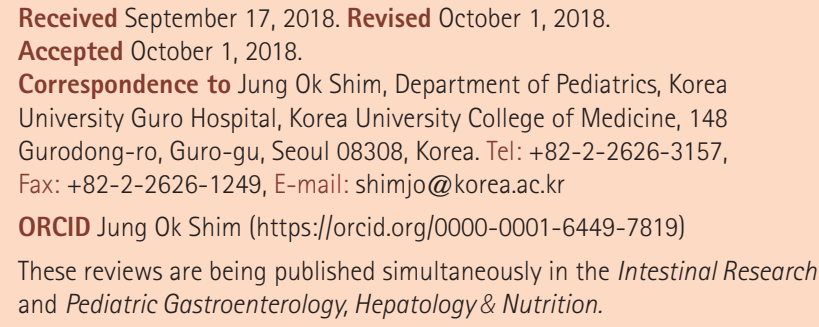

IBD. Particularly very early-onset IBD (VEO-IBD) or infantileonset IBD differs in many aspects, including the disease subtypes, location of the lesions, disease behavior, and genetically attributable risks. Several genetic defects that disturb intestinal epithelial barrier function or affect immune function have been noted in patients with VEO-IBD. ${ }^{1,3}$ This review examines the currently published data on the clinical and genetic characteristics of VEO-IBD, particularly focused on the VEO-IBD in Korea.

\section{EPIDEMIOLOGY OF PEDIATRIC IBD}

IBD can present at any age, with the most affected patients being in the age range of 15 to 29 years. ${ }^{4}$ It develops during childhood or adolescence in approximately $25 \%$ of the cases. ${ }^{5}$ The incidence of pediatric IBD, particularly $\mathrm{CD}$, has been increasing in both developed and developing nations. ${ }^{6}$ The annual in- 
cidence of pediatric IBD has been increasing in Western countries, with the annual incidence of 2.2-13.3 per 100,000 children. ${ }^{6-8}$ In Korea, according to the National Health Insurance Claim Data from 2006 to 2015, the annual incidence of CD is 3.6 per 100,000 at all ages and 5.2 per 100,000 children. The incidence of UC is 7.7 per 100,000 at all ages and 2.4 per 100,000 children. The incidence of CD in teenagers has been increased, while its incidence in children younger than 6 years has remained stable. Neonatal or infantile-onset IBD develops in less than $1 \%$ of pediatric patients. ${ }^{9}$ The annual incidence of IBD in children younger than 6 years was reported as 0.4 per 100,000 for CD and 0.9 per 100,000 for UC in 2009 in Canada, which had been increased by $7.4 \%$ per year since $1994 .^{7}$ However, this increased rate of diagnosis for pediatric IBD might be partially attributable to improvement in awareness and diagnostic accuracy. In a recent French study, VEO-IBD represented 3\% of pediatric IBD cases and its incidence remained stable from 1988 to $2011^{10}$ as in the Korean nationwide data. The stability of the incidence of VEO-IBD over time implies that this disease might not be strongly influenced by environmental factors.

\section{AGE OF ONSET}

The pediatric Paris classification uses an age cutoff of $<10$ years $(\mathrm{Ala})^{11}$ because of the paucity of ileal involvement, serological characteristics in $\mathrm{CD}$, and pancolitis in UC. Children with neonatal-onset IBD or infantile-onset IBD have high rates of affected first-degree relatives, a severe disease course, and a high rate of resistance to immunosuppressive treatment. Recently, subgroups of pediatric-onset IBD ( $<17$ years), early onset IBD ( $<10$ years), VEO-IBD ( $<6$ years), infantile onset IBD ( $<2$ years), and neonatal onset IBD ( $<28$ days) have been suggested (Table 1) based on the phenotypic characteristics including disease location and severity, in addition to the presence of monogenic defects. ${ }^{3,12}$

Table 1. Subgroups of Pediatric IBD

\begin{tabular}{lll}
\hline Subgroups & Previous classification & Age of onset \\
\hline Pediatric-onset IBD & Montreal classification A1 & $<17 \mathrm{yr}$ \\
& Paris classification A1b & \\
Early-onset IBD & Paris classification A1a & $<10 \mathrm{yr}$ \\
Very early-onset IBD & & $<6 \mathrm{yr}$ \\
Infantile-onset IBD & $<2 \mathrm{yr}$ \\
Neonatal IBD & & $<28$ day of age \\
\hline
\end{tabular}

\section{GENETICS OF VEO-IBD}

Genetic predisposition might play an important role in development of IBD particularly in young children. Twin and family studies suggested that the risk of developing CD in another sibling is 26 -fold higher than in an unrelated person, compared with a 9-fold increase for UC development. ${ }^{13}$ Large-scaled genome-wide association studies (GWAS) have detected 250 single-nucleotide polymorphisms associated with IBD, and a recent trans-ancestry association study identified 38 additional new loci influencing the risk of developing IBD. ${ }^{14,15}$ Ethnic differences have also been reported, since NOD2/CARD15 was reported as a susceptible gene locus in Caucasians, but not in Asians, while ATG16L2 and IL17REL were reported as susceptible loci in Korean. ${ }^{16}$ A GWAS in children showed similar results as in adults. ${ }^{17}$ Older children and adults shares similar polygenic forms of IBD. The main limitation of GWAS is that the evidence of causality is largely absent and it tend to find common variants, so it may overlook functionally detrimental variations imposed by rare mutations. VEO-IBD patients may carry a wide spectrum of low frequency gene variants.

Glocker et al. ${ }^{18}$ were the first to identify mendelian mutations of $I L-10 R A$ and $I L-10 R B$ in children with infantile-onset IBD, which provided a new insight into the pathogenesis of IBD. Interleukin 10 (IL-10) is critical in maintaining the balance of the immune system, where it restricts and terminates immune responses by limiting the secretion of pro-inflammatory cytokines such as TNF- $\alpha$, IL-1, IL-6, IL-12, and controls both the differentiation and proliferation of macrophages, $\mathrm{T}$ cells and B cells. Due to its unique role in balancing the immune system, IL-10 has a long history as the focal point in IBD research. Shim et al. ${ }^{19,20}$ reported 7 cases of Korean children with IL10RA mutations among 14 children with infantile-onset IBD. Children with IL10RA mutations showed Crohn's phenotypes, had anal fistulae, and required early surgical interventions since they exhibited a poor response to medical therapy. They also had recurrent infections, and folliculitis.

Whole exome sequencing (WES) has greatly expanded the list of genes associated with IBD risk beyond those identified during the GWAS era. Sequential candidate gene sequencing according to the disease phenotype could not identify new causative variants. WES allows the identification of causative mutations in rare diseases, although extensive filtering and bioinformatics are required to exclude the large numbers of benign variants and variants of unknown significance that tend to be identified by this approach. ${ }^{1}$ 
Table 2. List of Gene Mutations Associated with Monogenic Very Early-Onset IBD and IBD-like Colitis

\begin{tabular}{|c|c|c|}
\hline Disorder & Gene & Study (year) \\
\hline \multicolumn{3}{|l|}{ Immune dysregulation } \\
\hline IPEX & FOXP3 & Barzaghi et al. $(2012)^{23}$ \\
\hline \multirow[t]{2}{*}{ IPEX-like } & IL2RA & Caudy et al. $(2007)^{24}$ \\
\hline & STAT1 & Uzel et al. $(2013)^{25}$ \\
\hline \multirow[t]{2}{*}{ IL-10 signaling defects } & IL10RA & Glocker et al. (2009) ${ }^{18}$ \\
\hline & & Shim and Seo $(2014)^{19}$ \\
\hline IL-10 signaling defects & ILIORB & Glocker et al. (2009) \\
\hline IL-10 signaling defects & $1 L 10$ & Kotlarz et al. $(2012)^{26}$ \\
\hline NOD2 signaling defects & TRIM22 & Li et al. $(2016)^{27}$ \\
\hline \multicolumn{3}{|l|}{ Epithelial barrier function defects } \\
\hline ADAM17 deficiency & ADAM17 & Blaydon et al. $(2011)^{28}$ \\
\hline Dystrophic epidermolysis bullosa & COL7A1 & Freeman et al. $(2008)^{29}$ \\
\hline Epithelial NADPH oxidases defect & NOX1, DUOX2 & Hayes et al. $(2015)^{30}$ \\
\hline Familial diarrhea & GUCY2C & Fiskerstrand et al. $(2012)^{31}$ \\
\hline Kindler syndrome & FERMT1 & Freeman et al. $(2008)^{29}$ \\
\hline X-linked ectodermal immunodeficiency (NEMO) & $I K B K G$ & Cheng et al. $(2009)^{32}$ \\
\hline TTC7A deficiency & $\Pi C 7 A$ & Avitzur et al. $(2014)^{33}$ \\
\hline \multicolumn{3}{|l|}{ Phagocyte defects } \\
\hline \multirow[t]{4}{*}{ Chronic granulomatous disease } & $C Y B B, C Y B A$ & Schäppi et al. $(2001)^{34}$ \\
\hline & NCF1, NCF2, NCF4 & Matute et al. $(2009)^{35}$ \\
\hline & LACC1 & Al-Bousafy et al. $(2006)^{36}$ \\
\hline & & Huang et al. $(2016)^{37}$ \\
\hline Congenital neutropenia & G6PC3 & Bégin et al. $(2013)^{38}$ \\
\hline Glycogen storage disease $1 b$ & SLC37A4 & Visser et al. $(2000)^{39}$ \\
\hline Leukocyte adhesion deficiency 1 & ITGB2 & D'Agata et al. $(1996)^{40}$ \\
\hline \multicolumn{3}{|l|}{ Hyperinflammatory and autoimmune disorders } \\
\hline Autoimmune lymphoproliferative syndrome type 5 & CTLA4 & Kuehn et al. (2014) \\
\hline Familial hemophagocytic lymphohistiocytosis type 5 & STXBP2 & Meeths et al. $(2010)^{42}$ \\
\hline $\mathrm{XLP} 2$ & XIAP & Zeissig et al. $(2015)^{43}$ \\
\hline XLP1 & SH2DIA & Booth et al. $(2011)^{44}$ \\
\hline \multirow[t]{2}{*}{ Familial Mediterranean fever } & MEFV & Sari et al. $(2008)^{45}$ \\
\hline & & Villani et al. $(2009)^{46}$ \\
\hline \multirow[t]{3}{*}{ Hermansky-Pudlak 1,4,6 } & HPS1, & Hazzan et al. $(2006)^{47}$ \\
\hline & HPS4, & Anderson et al. $(2003)^{48}$ \\
\hline & HPS6 & Mora et al. $(2011)^{49}$ \\
\hline Multisystem autoimmune disease & STAT3 & Flanagan et al. $(2014)^{50}$ \\
\hline Mevalonate kinase deficiency & MVK & Bader-Meunier et al. $(2011)^{51}$ \\
\hline Phospholipase $\mathrm{C}-\gamma 2$ defects & PLCG2 & Zhou et al. $(2012)^{52}$ \\
\hline \multicolumn{3}{|l|}{ T-cell, B-cell, and complex function defect } \\
\hline \multirow[t]{2}{*}{ Agammaglobulinemia } & $B T K$ & Agarwal and Mayer (2009) $)^{53}$ \\
\hline & PIK3R1 & Conley et al. $(2012)^{54}$ \\
\hline
\end{tabular}


Table 2. Continued

\begin{tabular}{|c|c|c|}
\hline Disorder & Gene & Study (year) \\
\hline CVID 1 & ICOS & Takahashi et al. (2009) ${ }^{55}$ \\
\hline CVID 8 & $\angle R B A$ & Burns et al. $(2012)^{56}$ \\
\hline \multirow[t]{2}{*}{ Hoyeraal-Hreidarsson syndrome } & $D K C 1$ & Knight et al. $(1999)^{58}$ \\
\hline & RTEL1 & Ballew et al. $(2013)^{59}$ \\
\hline \multirow[t]{2}{*}{ Hyper IgM syndrome } & CD4OLG & Levy et al. $(1997)^{61}$ \\
\hline & AICDA & Quartier et al. $(2004)^{62}$ \\
\hline Immunodeficiency 17 & CD3G & Arnaiz-Villena et al. (1992) ${ }^{63}$ \\
\hline \multirow[t]{2}{*}{ SCID } & $Z A P 70, I L 2 R G$ & Chan et al. $(2016)^{64}$ \\
\hline & & de Saint Basile et al. $(2004)^{68}$ \\
\hline SCID/hyper lgM syndrome & RAG2 & Felgentreff et al. $(2011)^{66}$ \\
\hline \multirow[t]{2}{*}{ Omenn syndrome } & $D C L R E I X$ & Rohr et al. $(2010)^{69}$ \\
\hline & $D C L R E 1 C$ & Moshous et al. $(2001)^{70}$ \\
\hline Wiscott-Aldrich syndrome & WAS & Catucci et al. (2012) \\
\hline \multicolumn{3}{|l|}{ Others } \\
\hline MASP deficiency & MASP2 & Stengaard-Pedersen et al. $(2003)^{72}$ \\
\hline Trichohepatoenteric syndrome & SKIV2L, TTC37 & Fabre et al. $(2012)^{73}$ \\
\hline
\end{tabular}

The diagnostic approach to monogenic very early-onset IBD. Some data were adapted from Uhlig et al., ${ }^{3}$ and others were updated. IPEX, X-linked immune dysregulation, polyendocrinopathy, and enteropathy; IL, interleukin; XLP, X-linked lymphoproliferative syndrome; CVID, common variable immunodeficiency; $S C I D$, severe combined immunodeficiency.

Studies using WES have identified mutations in the gene encoding X-linked inhibitor of apoptosis (XIAP) in infants with aggressive colitis, perianal fistulae, and refractory IBD. ${ }^{21,22}$ Such symptoms often present between 2 and 6 years of age. $\mathrm{XIAP}$ regulates apoptosis and nuclear factor- $\mathrm{\kappa B}$ activation, and it is expressed in all hematopoietic cells; therefore, mutations in this protein may also cause the development of an Xlinked lymphoproliferative syndrome and hemophagocytic lymphohistiocytosis.

To date, approximately 60 monogenic mutations associated with IBD and IBD-like colitis have been identified (Table 2).,3,23-73 Mutations related in genes associated with epithelial barrier function, such as TTC7A have been identified. ${ }^{33}$ Monogenic mutations have also been observed in diseases with phagocyte defects, such as chronic granulomatous disease (CYBB, CYBA, $N C F 1, N C F 2$, and NCF4) $)^{34-36}$ and congenital neutropenia (G6PC3)..$^{38}$ About $40 \%$ of chronic granulomatous disease cases develop CD-like inflammation. ${ }^{3}$ Other IBD-associated mu- tations have been implicated in hyper- or autoinflammatory disorders, including XIAP deficiency. Genetic disorders involving defects in $\mathrm{T}$ and B cell function, such as Wiskott-Aldrich syndrome (WAS) ${ }^{74}$ and severe combined immunodeficiency disorder $^{59}$ can present with IBD-like phenotypes. Furthermore, mutations associated with X-linked immune dysregulation, polyendocrinopathy, and enteropathy (IPEX) have been found such as those in FOXP3. ${ }^{75}$

Monogenic mutations have been found mostly in children with an age of onset under 6 years, whereas conventional polygenic IBD more commonly has an age of onset older than 7 years.

\section{CLINICAL ASPECTS OF VEO-IBD AND MONOGENIC IBD}

In many cases of VEO-IBD, we should consider the potential differential diagnoses of cow milk protein allergy, eosinophilic 
gastroenteritis, infectious causes, and primary immune deficiency with intestinal inflammation. High levels of IgE or eosinophilia can also be found in patients with monogenic IBD and IBD-like phenotype (defects in FOXP3, IL2RA, IKBKG, WAS, or DOCK 8$)^{3}{ }^{3}$

The frequency of IBD-unclassified was reported as $7 \%$ in VEO-IBD, compared to $2 \%$ in early-onset (EO)-IBD. ${ }^{10}$ Furthermore, in $25 \%$ of the children with VEO-IBD originally diagnosed as UC or IBD-unclassified, the diagnosis was reclassified to CD over time. ${ }^{76}$ Children with VEO-IBD more commonly showed rectal bleeding and mucous stools, whereas weight loss and abdominal pain were more frequent in those with EO-IBD. Isolated colonic disease was more common among the patients with VEO-CD. ${ }^{10}$

The next concern is why monogenic IBD is important. Monogenic IBD usually presents with refractory IBD or fistulous $\mathrm{CD}$, so early treatment with biologics, or an unconventional approach such as hematopoietic stem cell transplantation (SCT) might be needed. Patients that do not respond to conventional treatment, those with high mortality, and those that have an increased susceptibility to hematopoietic cancers such as patients with IL-10 signaling defects, IPEX, WAS, and XIAP deficiency can be candidates for SCT. ${ }^{3}$ However, in a child with TTC7A deficiency, multiple intestinal atresia recurred after SCT, and he died. ${ }^{77}$ Therefore, it is important to determine the genetic basis of the disease for each patient before selecting SCT.

When we suspect monogenic IBD, the most important clinical sign is a young age of onset. In addition, lack of a response to conventional medication, a family history of IBD, autoimmunity, recurrent infections, perianal disease, hemophagocytic lymphohistiocytosis, intestinal obstruction, skin lesions, and tumors can be signs of monogenic IBD.

To diagnose monogenic IBD, sequential candidate gene sequencing can be costly and time- consuming. WES can be used for the analysis of patients with suspected monogenic IBD despite some limitations. The targeted next-generation sequencing of multiple candidate genes can also be an alternative option.

\section{MONOGENIC IBD VERSUS VEO-IBD}

In a Canadian nationwide epidemiology study, there was no difference in the rate of surgery over time between children aged less than 6 years and children aged between 6 and 9 years. ${ }^{78}$ Meanwhile, in the aforementioned study by Shim and
Seo, ${ }^{19}$ the clinical courses of children with VEO-IBD involving IL10RA mutations were refractory, whereas those of children with VEO-IBD without such mutations were not different from those of children with EO-IBD. Kim et al. ${ }^{79}$ reported that patients with monogenic VEO-IBD showed a higher morbidity than those with non-monogenic VEO-IBD or non-monogenic pediatric IBD. Whether VEO-IBD patients have low response rates to conventional therapy, or a more aggressive phenotype is controversial. It seems that the age of onset itself does not sufficiently predict the severity of the disease or the response to therapy. Crucially, the main determinant of an individual prognosis is the specific causative gene mutation.

\section{CONCLUSIONS}

Monogenic IBD in patients with VEO-IBD is a different disease entity from EO-IBD, pediatric IBD, and adult-onset IBD. Monogenic VEO-IBD has high rates of morbidity and mortality, and it might require different treatment strategies. Moreover, monogenic VEO-IBD might be a fundamentally different disease entity from non-monogenic forms of VEO-IBD. Welldesigned global studies are needed to investigate this hypothesis.

\section{FINANCIAL SUPPORT}

Jung Ok Shim received the grant of National Research Foundation of Korea (Grant No. NRF-2018R1C1B5047245).

\section{CONFLICT OF INTEREST}

No potential conflict of interest relevant to this article was reported.

\section{AUTHOR CONTRIBUTION}

Conception and drafting of manuscript: Shim JO.

\section{REFERENCES}

1. Moran CJ. Very early onset inflammatory bowel disease. Semin Pediatr Surg 2017;26:356-359.

2. Seo JK. Pediatric inflammatory bowel disease (IBD): phenotypic, genetic and therapeutic differences between early-onset and adult-onset IBD. Korean J Pediatr Gastroenterol Nutr 2011; 14:1-25. 
3. Uhlig HH, Schwerd T, Koletzko S, et al. The diagnostic approach to monogenic very early onset inflammatory bowel disease. Gastroenterology 2014;147:990-1007.e3.

4. Ekbom A, Helmick C, Zack M, Adami HO. The epidemiology of inflammatory bowel disease: a large, population-based study in Sweden. Gastroenterology 1991;100:350-358.

5. Loftus EV Jr. Clinical epidemiology of inflammatory bowel disease: incidence, prevalence, and environmental influences. Gastroenterology 2004;126:1504-1517.

6. Benchimol EI, Fortinsky KJ, Gozdyra P, Van den Heuvel M, Van Limbergen J, Griffiths AM. Epidemiology of pediatric inflammatory bowel disease: a systematic review of international trends. Inflamm Bowel Dis 2011;17:423-439.

7. Benchimol EI, Manuel DG, Guttmann A, et al. Changing age demographics of inflammatory bowel disease in Ontario, Canada: a population-based cohort study of epidemiology trends. Inflamm Bowel Dis 2014;20:1761-1769.

8. Grieci T, Bütter A. The incidence of inflammatory bowel disease in the pediatric population of Southwestern Ontario. J Pediatr Surg 2009;44:977-980.

9. Shim JO, Han K. Treatment patterns and prognosis of inflammatory bowel disease: a nationwide epidemiologic study. Gut Liver 2017;11 Suppl 1:100.

10. Bequet E, Sarter H, Fumery M, et al. Incidence and phenotype at diagnosis of very-early-onset compared with later-onset paediatric inflammatory bowel disease: a population-based study [1988-2011]. J Crohns Colitis 2017;11:519-526.

11. Levine A, Griffiths A, Markowitz J, et al. Pediatric modification of the Montreal classification for inflammatory bowel disease: the Paris classification. Inflamm Bowel Dis 2011;17:1314-1321.

12. Hyams JS. Standardized recording of parameters related to the natural history of inflammatory bowel disease: from Montreal to Paris. Dig Dis 2014;32:337-344.

13. Doecke JD, Simms LA, Zhao ZZ, et al. Genetic susceptibility in IBD: overlap between ulcerative colitis and Crohn's disease. Inflamm Bowel Dis 2013;19:240-245.

14. Liu JZ, van Sommeren S, Huang H, et al. Association analyses identify 38 susceptibility loci for inflammatory bowel disease and highlight shared genetic risk across populations. Nat Genet 2015;47:979-986.

15. Zhang Y, Tian L, Sleiman P, et al. Bayesian analysis of genomewide inflammatory bowel disease data sets reveals new risk loci. Eur J Hum Genet 2018;26:265-274.

16. Yang SK, Hong M, Zhao W, et al. Genome-wide association study of Crohn's disease in Koreans revealed three new susceptibility loci and common attributes of genetic susceptibili- ty across ethnic populations. Gut 2014;63:80-87.

17. Essers JB, Lee JJ, Kugathasan S, et al. Established genetic risk factors do not distinguish early and later onset Crohn's disease. Inflamm Bowel Dis 2009;15:1508-1514.

18. Glocker EO, Kotlarz D, Boztug K, et al. Inflammatory bowel disease and mutations affecting the interleukin-10 receptor. N Engl J Med 2009;361:2033-2045.

19. Shim JO, Seo JK. Very early-onset inflammatory bowel disease (IBD) in infancy is a different disease entity from adultonset IBD; one form of interleukin-10 receptor mutations. J Hum Genet 2014;59:337-341.

20. Shim JO, Hwang S, Yang HR, et al. Interleukin-10 receptor mutations in children with neonatal-onset Crohn's disease and intractable ulcerating enterocolitis. Eur J Gastroenterol Hepatol 2013;25:1235-1240.

21. Worthey EA, Mayer AN, Syverson GD, et al. Making a definitive diagnosis: successful clinical application of whole exome sequencing in a child with intractable inflammatory bowel disease. Genet Med 2011;13:255-262.

22. Kim SC. Monozygotic twin cases of XIAP deficiency syndrome. J Pediatr Gastroenterol Nutr 2018;67:e101.

23. Barzaghi F, Passerini L, Bacchetta R. Immune dysregulation, polyendocrinopathy, enteropathy, X-linked syndrome: a paradigm of immunodeficiency with autoimmunity. Front Immunol 2012;3:211.

24. Caudy AA, Reddy ST, Chatila T, Atkinson JP, Verbsky JW. CD25 deficiency causes an immune dysregulation, polyendocrinopathy, enteropathy, X-linked-like syndrome, and defective IL-10 expression from CD4 lymphocytes. J Allergy Clin Immunol 2007;119:482-487.

25. Uzel G, Sampaio EP, Lawrence MG, et al. Dominant gain-offunction STAT1 mutations in FOXP3 wild-type immune dysregulation-polyendocrinopathy-enteropathy-X-linked-like syndrome. J Allergy Clin Immunol 2013;131:1611-1623.

26. Kotlarz D, Beier R, Murugan D, et al. Loss of interleukin-10 signaling and infantile inflammatory bowel disease: implications for diagnosis and therapy. Gastroenterology 2012;143: 347-355.

27. Li Q, Lee CH, Peters LA, et al. Variants in TRIM22 that affect NOD2 signaling are associated with very-early-onset inflammatory bowel disease. Gastroenterology 2016;150:1 196-1207.

28. Blaydon DC, Biancheri P, Di WL, et al. Inflammatory skin and bowel disease linked to ADAM17 deletion. N Engl J Med 2011; 365:1502-1508.

29. Freeman EB, Köglmeier J, Martinez AE, et al. Gastrointestinal complications of epidermolysis bullosa in children. Br J Der- 
matol 2008;158:1308-1314.

30. Hayes P, Dhillon S, O'Neill K, et al. Defects in NADPH oxidase genes NOX1 and DUOX2 in very early onset inflammatory bowel disease. Cell Mol Gastroenterol Hepatol 2015;1:489502.

31. Fiskerstrand T, Arshad N, Haukanes BI, et al. Familial diarrhea syndrome caused by an activating GUCY2C mutation. N Engl J Med 2012;366:1586-1595.

32. Cheng LE, Kanwar B, Tcheurekdjian H, et al. Persistent systemic inflammation and atypical enterocolitis in patients with NEMO syndrome. Clin Immunol 2009;132:124-131.

33. Avitzur Y, Guo C, Mastropaolo LA, et al. Mutations in tetratricopeptide repeat domain $7 \mathrm{~A}$ result in a severe form of very early onset inflammatory bowel disease. Gastroenterology 2014;146:1028-1039.

34. Schäppi MG, Smith VV, Goldblatt D, Lindley KJ, Milla PJ. Colitis in chronic granulomatous disease. Arch Dis Child 2001;84: 147-151.

35. Matute JD, Arias AA, Wright NA, et al. A new genetic subgroup of chronic granulomatous disease with autosomal recessive mutations in p40 phox and selective defects in neutrophil NADPH oxidase activity. Blood 2009;114:3309-3315.

36. Al-Bousafy A, Al-Tubuly A, Dawi E, Zaroog S, Schulze I. Libyan boy with autosomal recessive trait (P22-phox defect) of chronic granulomatous disease. Libyan J Med 2006;1:162-171.

37. Huang C, De Ravin SS, Paul AR, et al. Genetic risk for inflammatory bowel disease is a determinant of Crohn's disease development in chronic granulomatous disease. Inflamm Bowel Dis 2016;22:2794-2801.

38. Bégin P, Patey N, Mueller P, et al. Inflammatory bowel disease and T cell lymphopenia in G6PC3 deficiency. J Clin Immunol 2013;33:520-525.

39. Visser G, Rake JP, Fernandes J, et al. Neutropenia, neutrophil dysfunction, and inflammatory bowel disease in glycogen storage disease type Ib: results of the European Study on Glycogen Storage Disease type I. J Pediatr 2000;137:187-191.

40. D’Agata ID, Paradis K, Chad Z, Bonny Y, Seidman E. Leucocyte adhesion deficiency presenting as a chronic ileocolitis. Gut 1996;39:605-608.

41. Kuehn HS, Ouyang W, Lo B, et al. Immune dysregulation in human subjects with heterozygous germline mutations in CTLA4. Science 2014;345:1623-1627.

42. Meeths M, Entesarian M, Al-Herz W, et al. Spectrum of clinical presentations in familial hemophagocytic lymphohistiocytosis type 5 patients with mutations in STXBP2. Blood 2010;116: 2635-2643.
43. Zeissig Y, Petersen BS, Milutinovic S, et al. XIAP variants in male Crohn's disease. Gut 2015;64:66-76.

44. Booth C, Gilmour KC, Veys P, et al. X-linked lymphoproliferative disease due to SAP/SH2D1A deficiency: a multicenter study on the manifestations, management and outcome of the disease. Blood 2011;117:53-62.

45. Sari S, Egritas O, Dalgic B. The familial Mediterranean fever (MEFV) gene may be a modifier factor of inflammatory bowel disease in infancy. Eur J Pediatr 2008;167:391-393.

46. Villani AC, Lemire M, Louis E, et al. Genetic variation in the familial Mediterranean fever gene (MEFV) and risk for Crohn's disease and ulcerative colitis. PLoS One 2009;4:e7154.

47. Hazzan D, Seward S, Stock H, et al. Crohn's-like colitis, enterocolitis and perianal disease in Hermansky-Pudlak syndrome. Colorectal Dis 2006;8:539-543.

48. Anderson PD, Huizing M, Claassen DA, White J, Gahl WA. Hermansky-Pudlak syndrome type 4 (HPS-4): clinical and molecular characteristics. Hum Genet 2003;113:10-17.

49. Mora AJ, Wolfsohn DM. The management of gastrointestinal disease in Hermansky-Pudlak syndrome. J Clin Gastroenterol 2011;45:700-702.

50. Flanagan SE, Haapaniemi E, Russell MA, et al. Activating germline mutations in STAT3 cause early-onset multi-organ autoimmune disease. Nat Genet 2014;46:812-814.

51. Bader-Meunier B, Florkin B, Sibilia J, et al. Mevalonate kinase deficiency: a survey of 50 patients. Pediatrics 2011;128:e152e159.

52. Zhou Q, Lee GS, Brady J, et al. A hypermorphic missense mutation in PLCG2, encoding phospholipase Cgamma2, causes a dominantly inherited autoinflammatory disease with immunodeficiency. Am J Hum Genet 2012;91:713-720.

53. Agarwal S, Mayer L. Pathogenesis and treatment of gastrointestinal disease in antibody deficiency syndromes. J Allergy Clin Immunol 2009;124:658-664.

54. Conley ME, Dobbs AK, Quintana AM, et al. Agammaglobulinemia and absent B lineage cells in a patient lacking the p85alpha subunit of PI3K. J Exp Med 2012;209:463-470.

55. Takahashi N, Matsumoto K, Saito H, et al. Impaired CD4 and CD8 effector function and decreased memory $\mathrm{T}$ cell populations in ICOS-deficient patients. J Immunol 2009;182:55155527.

56. Burns SO, Zenner HL, Plagnol V, et al. LRBA gene deletion in a patient presenting with autoimmunity without hypogammaglobulinemia. J Allergy Clin Immunol 2012;130:1428-1432.

57. Salzer E, Kansu A, Sic H, et al. Early-onset inflammatory bowel disease and common variable immunodeficiency-like disease 
caused by IL-21 deficiency. J Allergy Clin Immunol 2014;133: 1651-1659.

58. Knight SW, Heiss NS, Vulliamy TJ, et al. Unexplained aplastic anaemia, immunodeficiency, and cerebellar hypoplasia (Hoyeraal-Hreidarsson syndrome) due to mutations in the dyskeratosis congenita gene, DKC1. Br J Haematol 1999;107:335359.

59. Ballew BJ, Joseph V, De S, et al. A recessive founder mutation in regulator of telomere elongation helicase 1, RTEL1, underlies severe immunodeficiency and features of Hoyeraal Hreidarsson syndrome. PLoS Genet 2013;9:e1003695.

60. Sanal O, Jing H, Ozgur T, et al. Additional diverse findings expand the clinical presentation of DOCK8 deficiency. J Clin Immunol 2012;32:698-708.

61. Levy J, Espanol-Boren T, Thomas C, et al. Clinical spectrum of X-linked hyper-IgM syndrome. J Pediatr 1997;131(1 Pt 1):4754.

62. Quartier P, Bustamante J, Sanal O, et al. Clinical, immunologic and genetic analysis of 29 patients with autosomal recessive hyper-IgM syndrome due to activation-induced cytidine deaminase deficiency. Clin Immunol 2004;110:22-29.

63. Arnaiz-Villena A, Timon M, Corell A, Perez-Aciego P, MartinVilla JM, Regueiro JR. Brief report: primary immunodeficiency caused by mutations in the gene encoding the CD3-gamma subunit of the T-lymphocyte receptor. N Engl J Med 1992;327: 529-533.

64. Chan AY, Punwani D, Kadlecek TA, et al. A novel human autoimmune syndrome caused by combined hypomorphic and activating mutations in ZAP-70. J Exp Med 2016;213:155-165.

65. de Saint-Basile G, Le Deist F, Caniglia M, Lebranchu Y, Griscelli C, Fischer A. Genetic study of a new X-linked recessive immunodeficiency syndrome. J Clin Invest 1992;89:861-866.

66. Felgentreff K, Perez-Becker R, Speckmann C, et al. Clinical and immunological manifestations of patients with atypical severe combined immunodeficiency. Clin Immunol 2011; 141:73-82.

67. Ozgür TT, Asal GT, Cetinkaya D, et al. Hematopoietic stem cell transplantation in a CD3 gamma-deficient infant with inflammatory bowel disease. Pediatr Transplant 2008;12:910913.

68. de Saint Basile G, Geissmann F, Flori E, et al. Severe combined immunodeficiency caused by deficiency in either the delta or the epsilon subunit of CD3. J Clin Invest 2004;114:1512-1517.

69. Rohr J, Pannicke U, Döring M, et al. Chronic inflammatory bowel disease as key manifestation of atypical ARTEMIS deficiency. J Clin Immunol 2010;30:314-320.

70. Moshous D, Callebaut I, de Chasseval R, et al. Artemis, a novel DNA double-strand break repair/V(D)J recombination protein, is mutated in human severe combined immune deficiency. Cell 2001;105:177-186.

71. Catucci M, Castiello MC, Pala F, Bosticardo M, Villa A. Autoimmunity in Wiskott-Aldrich syndrome: an unsolved enigma. Front Immunol 2012;3:209.

72. Stengaard-Pedersen K, Thiel S, Gadjeva M, et al. Inherited deficiency of mannan-binding lectin-associated serine protease 2. N Engl J Med 2003;349:554-560.

73. Fabre A, Charroux B, Martinez-Vinson C, et al. SKIV2L mutations cause syndromic diarrhea, or trichohepatoenteric syndrome. Am J Hum Genet 2012;90:689-692.

74. Aiuti A, Biasco L, Scaramuzza S, et al. Lentiviral hematopoietic stem cell gene therapy in patients with Wiskott-Aldrich syndrome. Science 2013;341:1233151.

75. Barzaghi F, Passerini L, Gambineri E, et al. Demethylation analysis of the FOXP3 locus shows quantitative defects of regulatory T cells in IPEX-like syndrome. J Autoimmun 2012;38:4958.

76. Rialon KL, Crowley E, Seemann NM, Fahy AS, Muise A, Langer JC. Long-term outcomes for children with very early-onset colitis: implications for surgical management. J Pediatr Surg 2018;53:964-967.

77. Samuels ME, Majewski J, Alirezaie N, et al. Exome sequencing identifies mutations in the gene TTC7A in French-Canadian cases with hereditary multiple intestinal atresia. J Med Genet 2013;50:324-329.

78. Benchimol EI, Mack DR, Nguyen GC, et al. Incidence, outcomes, and health services burden of very early onset inflammatory bowel disease. Gastroenterology 2014;147:803-813.

79. Kim KY, Lee EJ, Kim JW, et al. Higher morbidity of monogenic inflammatory bowel disease compared to the adolescent onset inflammatory bowel disease. Pediatr Gastroenterol Hepatol Nutr 2018;21:34-42. 